\title{
Origin of Deoxyuridine Triphosphate in Bacillus subtilis Infected with Bacteriophage PBS1
}

\author{
By B. K. RIMA* AND I. TAKAHASHI \\ Department of Biology, McMaster University, Hamilton, Ontario L8S 4K1, Canada
}

(Received 9 August 1978)

\begin{abstract}
dCyd deaminase and dUrd kinase did not appear to be important in the synthesis of dUTP in Bacillus subtilis infected with phage PBS1. PBS1 infection did not affect the activities of dCyd kinase, dCyd deaminase, dCMP deaminase and ribonucleotide reductase. $\mathrm{dUTP}$ in PBS1-infected cells was apparently formed by the action of dCTP deaminase induced by PBS1, by host dCMP deaminase and by host UTP reductase. By labelling the phage DNA with radioactive precursors in hosts carrying various pyrimidine mutations, it was found that about $50 \%$ of dUTP was derived from UTP reduction, $30 \%$ from dCTP deamination and $20 \%$ from dCMP deamination.
\end{abstract}

\section{INTRODUCTION}

In the DNA of transducing phage PBS1 for Bacillus subtilis, dTMP is completely replaced by dUMP (Takahashi \& Marmur, 1963). Thus, one would expect significant changes in enzymes involved in pyrimidine metabolism in host cells infected with this phage. Kahan (1963) observed high levels of thymidine monophosphatase and dUMP kinase in PBS1infected cells, and Tomita \& Takahashi (1976) found that the level of thymidine triphosphatase increased very rapidly soon after PBS1 infection. These enzyme activities would greatly reduce the size of the dTTP pool in the cells. Furthermore, a novel enzyme, dCTP deaminase which would yield dUTP directly from dCTP, was found in PBS1-infected cells (Tomita \& Takahashi, 1969). It was also reported that the levels of dCyd deaminase, dUrd kinase and ribonucleotide reductase did not change after phage infection (Tomita \& Takahashi, 1969). Recently, a deaminase activity for deoxycytidylate has been reported for B. subtilis (Rima \& Takahashi, 1978a) and dCMP seems to be the substrate. Therefore, dUTP in PBS1-infected cells is apparently formed by deamination of dCTP, deamination of dCMP (Rima \& Takahashi, 1978 a) and reduction of UTP (Rima \& Takahashi, 1978 b).

The present study was undertaken to determine whether other enzymes, such as dCyd deaminase and dUrd kinase, are important in the synthesis of dUTP. The contribution of dCTP deaminase, dCMP deaminase and UTP reductase was also determined by labelling PBS1 DNA with radioactive pyrimidine compounds in mutant strains affected in various steps of pyrimidine metabolism.

\section{METHODS}

Genetic symbols. dns, Mutants requiring deoxyribonucleosides; pyrG, deficient in CTP synthetase; cdd, deficient in deoxycytidine-cytidine deaminase; $d c k$, deficient in deoxycytidine kinase; $c r k$, deficient in cytidine kinase; $d d d$, deficient in deoxycytidylate deaminase.

Bacterial strains. Bacterial strains and culture media were described previously (Rima \& Takahashi, 1977). All mutant strains carried a $t s A$ mutation which is not relevant to the present work.

Bacteriophage. Phage PBS1 (Takahashi, 1961) was from our laboratory stock. Since in synthetic media the number of phage-producing bacteria was extremely small, Difco Penassay Broth (PA) was used.

Phage lysates, prepared as described by Takahashi (1963), were centrifuged at $7000 \mathrm{~g}$ for $15 \mathrm{~min}$ to remove

* Present address: Department of Biochemistry, The Queen's University of Belfast, Belfast BT9 7BL, Northern Ireland. 
cell debris. The supernatant fluid was centrifuged at $40000 \mathrm{~g}$ for $60 \mathrm{~min}$. The pellet was resuspended in buffer containing $0.02 \mathrm{M}-\mathrm{Tris} / \mathrm{HCl}(\mathrm{pH} 7.5), 0.1 \mathrm{M}-\mathrm{NaCl}$ and $0.01 \mathrm{M}-\mathrm{MgSO}_{4}$ and incubated with lysozyme $(100 \mu \mathrm{g}$ $\left.\mathrm{ml}^{-1}\right)$, pancreatic deoxyribonuclease $\left(10 \mu \mathrm{g} \mathrm{ml}^{-1}\right)$ and ribonuclease $\left(10 \mu \mathrm{g} \mathrm{ml}^{-1}\right)$ at $37^{\circ} \mathrm{C}$ for $30 \mathrm{~min}$. The phage particles were collected again by centrifugation at $40000 \mathrm{~g}$ for $60 \mathrm{~min}$ and suspended in $1 \times \mathrm{SSC}$ buffer $(0.15 \mathrm{M}-\mathrm{NaCl}$ and $0.015 \mathrm{M}$-sodium citrate, $\mathrm{pH}$ 7.2). Phage particles were further purified by centrifugation in $\mathrm{CsCl}$ density gradients (Yamagishi \& Takahashi, 1968). The banded phage particles were removed from the centrifuge tube with a syringe, diluted five-fold with PA medium and stored at $4{ }^{\circ} \mathrm{C}$.

Determination of specific radioactivities of $d U M P$ and dCMP in PBS1 DNA. Bacteria were grown in PA to the late-exponential phase and infected with PBS1 at a multiplicity of infection of 4. Two min before the addition of radioactive material, unlabelled Cyd and Ura were added to the cultures at a final concentration of $2 \mu \mathrm{g} \mathrm{ml}^{-1}$ each to lower the specific activity of the radioactive compounds. Under these conditions less than $10 \%$ of the added radioactivity was incorporated throughout the course of the experiment. This was necessary to obtain uniformly labelled progeny particles. If the non-radioactive compounds were not added, all the radioactivity was incorporated into nucleic acids in less than $10 \mathrm{~min}$. Radioactive bases or nucleosides were added $18 \mathrm{~min}$ after infection, i.e. at the time when phage DNA synthesis begins (Rima \& Takahashi, 1973). Lysis was complete between 50 and 70 min after infection. Cell debris was removed by centrifugation at $7000 \mathrm{~g}$ for $10 \mathrm{~min}$. The labelled phage particles were collected by centrifugation at $40000 \mathrm{~g}$ for $60 \mathrm{~min}$ together with carrier phages corresponding to $2 \times 10^{10}$ plaque-forming units. The phage pellet was resuspended and treated with lysozyme, deoxyribonuclease and ribonuclease as described above. The phage suspension was then lysed with sodium lauryl sulphate at $0.45 \%(\mathrm{w} / \mathrm{v})$ to release DNA. The samples were treated twice with an equal volume of phenol saturated with $1 \times \mathrm{SSC}$ buffer. The aqueous layer containing DNA was separated by centrifugation, and phenol was removed by extensive dialysis in $1 \times$ SSC buffer. The dialysate was treated with potassium hydroxide $(0.3 \mathrm{M})$ for $18 \mathrm{~h}$ at $37^{\circ} \mathrm{C}$ to hydrolyse RNA. The phage DNA was precipitated together with $200 \mu \mathrm{g}$ of unlabelled B. subtilis DNA and hydrolysed with pancreatic deoxyribonuclease and snake-venom phosphodiesterase by the procedure of Wu \& Kaiser (1967). After hydrolysis, the products were separated by paper chromatography. Samples of 10 to $100 \mu 1$ were spotted on Whatman no. 1 paper, and the chromatogram was developed with propan-2-ol/HCl/water $(170: 41: 28$, by vol.). The spots containing dUMP and dCMP were cut out and their radioactivities were determined. In all cases less than $2 \%$ of the radioactivity remained at the origin of the chromatogram. The ratio of c.p.m. in dUMP to that in dCMP was corrected for the relative abundance of dUMP $(36 \%)$ and dCMP (14\%) in PBS1 DNA (Takahashi \& Marmur, 1963) inorder to obtain the ratio of the specific radioactivities of these two nucleotides in the phage DNA.

\section{RESULTS}

\section{Role of various enzymes in the formation of dUTP}

We have previously reported that the activity of dUrd kinase does not change in $B$. subtilis after infection by PBS1 (Tomita \& Takahashi, 1969), and we have suggested that in uninfected $B$. subtilis dUrd kinase plays only a minor role in the metabolism of dUrd and that dUrd is rapidly broken down to Ura and deoxyribose 1-phosphate (Rima \& Takahashi, 1977). To investigate further the role of dUrd kinase in the synthesis of dUTP, PBS1 DNA was labelled with $\left[6-{ }^{3} \mathrm{H}\right] \mathrm{Ura}$ or $\left[6-{ }^{3} \mathrm{H}\right] \mathrm{dUrd}$ in a $p y r G$ mutant. The presence of the $p y r G$ mutation prevented the radioactivity of Ura or dUrd from being incorporated into dCMP of the phage DNA but the radioactivity could be incorporated into dUMP. Therefore, if dUrd kinase is induced by PBS1, more radioactivity should be incorporated into the DNA fraction with $\left[6-{ }^{3} \mathrm{H}\right] \mathrm{dUrd}$ than with $\left[6-{ }^{3} \mathrm{H}\right]$ Ura. Our results (Table 1 ) indicate that this was not the case, thus confirming our earlier observations.

To investigate the role of dCyd kinase and dCyd deaminase, the incorporation of $\left[5-{ }^{3} \mathrm{H}\right]$ $\mathrm{dCyd}$ in a $c d d-1$ pyrGl $d c k-4$ mutant infected with PBS1 was determined. Because of the $c d d$ and $d c k$ mutations, this strain is unable to metabolize dCyd either by deamination to $\mathrm{dUrd}$ or by phosphorylation to dCMP. If dCyd kinase or dCyd deaminase is induced by PBS1, a considerable amount of radioactivity should be incorporated into nucleic acids in PBS1-infected cells. If dCyd kinase is induced, the DNA fraction should be labelled; whereas if dCyd deaminase is induced, most radioactivity should be found in the RNA fraction. Our results (Table 2 ) indicate that practically no radioactivity was incorporated with this mutant (either infected or uninfected) when compared with the $d c k^{+}$parent 
Table 1. Incorporation of $\left[6-{ }^{3} H\right] d U r d$ and $\left[6-{ }^{3} H\right]$ Ura into nucleic acids of PBS1-infected cells

A $c d d-1$ pyrG1 dck-4 mutant was grown in PA supplemented with Cyd $\left(20 \mu \mathrm{g} \mathrm{ml}^{-1}\right)$. Bacteria in the late-exponential phase of growth were infected with PBS1 at a multiplicity of infection of 4 , and 25 min later $\left[6^{-3} \mathrm{H}\right] \mathrm{dUrd}$ or $\left[6^{-3} \mathrm{H}\right]$ Ura was added (final concentration $5 \mu \mathrm{Ci} \mathrm{ml}{ }^{-1}$ ). The incorporation of radioactive compounds was determined as described by Rima \& Takahashi $(1973,1977)$.

\begin{tabular}{|c|c|c|c|c|}
\hline & \multirow{2}{*}{$\begin{array}{l}\text { Time after } \\
\text { addition of } \\
\text { dUrd or Ura } \\
\quad \text { (min) }\end{array}$} & \multicolumn{2}{|c|}{ Radioactivity (c.p.m.) in: } & \multirow{2}{*}{$\begin{array}{l}\text { Percentage } \\
\text { of radio- } \\
\text { activity in } \\
\text { DNA }\end{array}$} \\
\hline & & $\begin{array}{l}\text { Total nucleic } \\
\text { acids }\end{array}$ & DNA & \\
\hline$\left[6-{ }^{3} \mathrm{H}\right] \mathrm{dUrd}$ & $\begin{array}{c}0 \\
7.5 \\
15.0\end{array}$ & $\begin{array}{r}61 \\
5866 \\
12733\end{array}$ & $\begin{array}{r}65 \\
610 \\
2137\end{array}$ & $\begin{array}{l}-\overline{10 \cdot 6} \\
16.8\end{array}$ \\
\hline$\left[6-{ }^{3} \mathrm{H}\right] \mathrm{Ura}$ & $\begin{array}{c}0 \\
7 \cdot 5 \\
15.0\end{array}$ & $\begin{array}{r}169 \\
6206 \\
18973\end{array}$ & $\begin{array}{r}191 \\
568 \\
4513\end{array}$ & $\begin{array}{r}\overline{9 \cdot 2} \\
23 \cdot 8\end{array}$ \\
\hline
\end{tabular}

Table 2. Effect of the dck mutation on the incorporation of $\left[5-{ }^{3} H\right] d C y d$

Mutants $c d d-1$ pyrGl and $c d d-1$ pyrGI dck-4 were grown in PA supplemented with Cyd $\left(20 \mu \mathrm{g} \mathrm{ml}^{-1}\right)$. Bacteria in the late-exponential phase of growth were infected with PBS1 at a multiplicity of infection of 4 and $20 \mathrm{~min}$ later $\left[5-{ }^{3} \mathrm{H}\right] \mathrm{dCyd}$ was added (final concentration $1.25 \mu \mathrm{Ci} \mathrm{ml}^{-1}$ ).

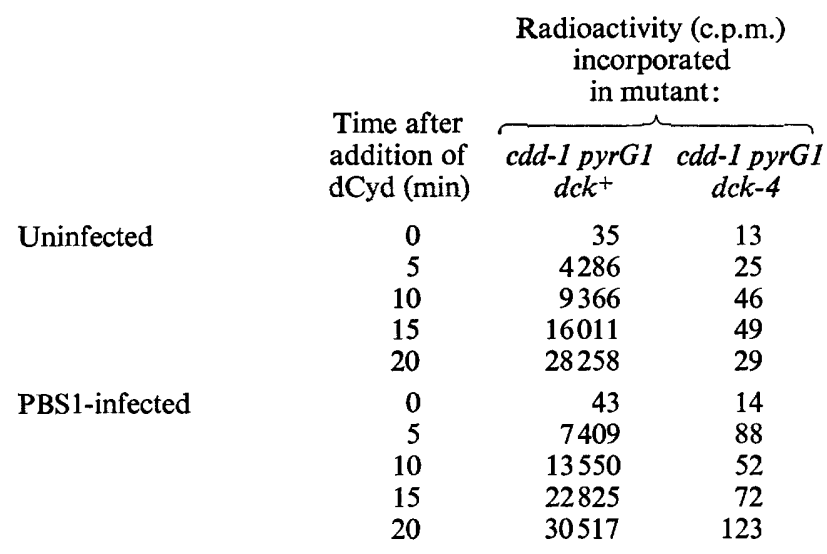

strain. It appears, therefore, that neither dCyd kinase nor dCyd deaminase is induced by PBS1 infection.

To determine whether dCMP deaminase of the host is affected by PBS1 infection, the activity of this enzyme was assayed by the method of Rima \& Takahashi (1978a). The host strain was a $c d d-1$ mutant from which a number of mutants used in the present study were derived. The activity in uninfected cell extracts was $70 \mathrm{nmol} \mathrm{h}^{-1}$ (mg protein) $)^{-1}$ and that in infected cell extracts prepared $25 \mathrm{~min}$ after infection was $80 \mathrm{nmol} \mathrm{h}^{-1}(\mathrm{mg} \text { protein })^{-1}$.

The activities of CTP reductase and UTP reductase were determined before and after PBS1 infection in a dns-6 mutant which showed low levels of CTP reductase (Rima \& Takahashi, $1978 \mathrm{~b})$. Both UTP reductase activity $\left[7 \mathrm{pmol} \mathrm{h}^{-\mathbf{1}}(\mathrm{mg} \text { protein })^{-1}\right]$ and CTP reductase activity $\left[0.35 \mathrm{nmol} \mathrm{h}^{-1}(\mathrm{mg} \text { protein })^{-1}\right]$ were unchanged after PBS1 infection.

\section{Origin of dUTP in PBS1-infected cells}

The metabolic pathways concerned in the synthesis of dUTP in $B$. subtilis are shown in Fig. 1 (Rima \& Takahashi, 1977, 1978a), phage-induced enzyme activities being indicated by dashed lines. According to these pathways, Ura or Urd cannot be used in the synthesis of dCTP in a host which carries a pyrG mutation. When PBS1 DNA was labelled with $\left[5-{ }^{3} \mathrm{H}\right] \mathrm{Ura}$ in the $c d d-1$ pyrG1 $d c k-4$ mutant, practically no radioactivity was found in the 


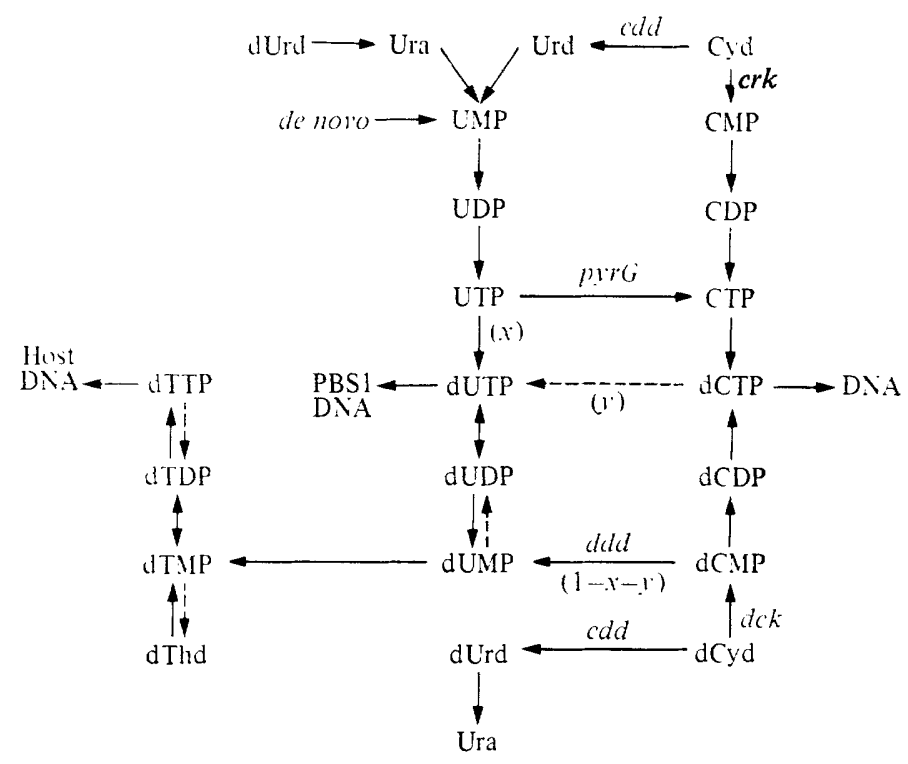

Fig. 1. Pyrimidine metabolism in B. subtilis infected with phage PBS1. Enzyme activities induced by PBS1 infection are indicated by dashed lines.

Table 3. The ratios $d U M P^{*} / d C M P^{*}$ in PBS1 DNA labelled with various pyrimidine compounds

Radioactive compounds were added at the following final concentrations: $\left[5-{ }^{3} \mathrm{H}\right] \mathrm{Ura}$ and $\left[5-{ }^{3} \mathrm{H}\right] \mathrm{Cyd}$, $5 \mu \mathrm{Ci} \mathrm{ml}{ }^{-1}$; [5- $\left.{ }^{3} \mathrm{H}\right] \mathrm{dCyd}, 1 \mu \mathrm{Ci} \mathrm{ml}^{-1}$; [5- $\left.{ }^{3} \mathrm{H}\right] \mathrm{Urd}$ and $\left[5-{ }^{3} \mathrm{H}\right] \mathrm{dUrd}, 10 \mu \mathrm{Ci} \mathrm{ml}^{-1}$.

dUMP*/dCMP* in PBS1 DNA labelled with radioactive compounds:

Strain

cdd-I pyrGI dck-4 cdd-1 dck-3 crk-1

SB19E (wild type)

$c d d-1$

cdd-1 dck-3

cdd-1 ddd-3

cdd-1 ddd-3 crk-3

$\begin{array}{ccccc}\text { Ura } & \text { dUrd } & \text { Urd } & \text { Cyd } & \text { dCyd } \\ 150 & - & - & - & - \\ 0.98 & - & 0.96 & \text { NP } & \text { NP } \\ - & 1.59 & 1.61 & - & 0.94 \\ 1.59 & - & - & 0.50 & 0.97 \\ 1.45 & - & - & 0.53 & \text { NP } \\ 1.21 & - & - & 0.44 & 0.58 \\ 0.89 & - & - & \text { NP } & 0.47\end{array}$

NP, Not possible; - , not done.

dCMP fraction of the phage DNA. Consequently, the ratio of the specific radioactivity of dUMP to that of dCMP (hereafter referred to as dUMP*/dCMP*) in PBS1 DNA was very high (Table 3 ).

Since $d c k$ and $c r k$ mutations prevent dilution of deoxyuridine and deoxycytidine nucleotides by exogenous pyrimidine compounds, PBS1 DNA labelled with radioactive Ura or Urd in a host carrying the above two mutations should show the same specific radioactivity for dUMP and dCMP. Indeed, the ratio dUMP*/dCMP* was 0.98 for $\left[5-{ }^{3} \mathrm{H}\right] \mathrm{Ura}$ and 0.96 for $\left[5-{ }^{3} \mathrm{H}\right]$ Urd in the $c d d-1 d c k-3$ crk-1 mutant (Table 3).

Since Ura, Urd and dUrd are converted to UMP before entering the nucleotide pool, the ratio dUMP*/dCMP* in PBS1 DNA should be the same when the DNA is labelled with these radioactive precursors. As shown in Table 3, a wild-type strain, SB19E, gave a ratio of about 1.6 with both $\left[5-{ }^{3} \mathrm{H}\right] \mathrm{Urd}$ and $\left[5-{ }^{3} \mathrm{H}\right] \mathrm{dU}$ rd. The same value was obtained when a $c d d-1$ mutant was labelled with $\left[5^{3} \mathrm{H}\right]$ Ura (Table 3 ).

When PBS1 DNA was labelled in a $c d d-1$ mutant, the ratio dUMP*/dCMP* was 0.50 with $\left[5-{ }^{3} \mathrm{H}\right] \mathrm{Cyd}$ and 0.97 with $\left[5-{ }^{3} \mathrm{H}\right] \mathrm{dCyd}$ (Table 3 ). This difference in the ratio suggests that deamination of dCMP also participates in the synthesis of dUTP. If there is no deamin- 
ation of dCMP, both radioactive dCyd and Cyd should give the same ratio of dUMP*/ dCMP* (see Fig. 1). Furthermore, the introduction of a $d d d$ mutation (deficiency in dCMP deaminase) into the above $c d d-1$ mutant resulted in a significant decrease in the ratio dUMP*/dCMP* (from 0.97 to 0.58 ) when the phage DNA was labelled with $\left[5-{ }^{3} \mathrm{H}\right] \mathrm{dCyd}$ (Table 3). This means that the $d d d$ mutation greatly decreased the size of the radioactive dUTP pool in phage-infected cells. Deamination of dCMP therefore seems to be important in the synthesis of dUTP. The product of dCMP deamination, dUMP, may be converted to dUTP by dUMP kinase (Kahan, 1963) induced by the phage. Therefore dUMP kinase appears to have a dual function-phosphorylation of dUMP, and elimination of the substrate (dUMP) for thymidylate synthetase which has been reported to be present in PBS1-infected cells (Tomita \& Takahashi, 1976).

If PBS1 DNA is labelled with radioactive Cyd in a mutant bearing $c d d$ and $d c k$, no UTP will be labelled. In addition, there will be no dilution in the dCMP and dCTP pool by exogenous dCyd. Therefore the ratio dUMP*/dCMP* in the DNA should reflect the fraction of dUTP derived from deoxycytidine nucleotides. This ratio was 0.53 in the $c d d-1 d c k-3$ mutant (Table 3), indicating that about $50 \%$ of dUTP is derived from deamination of dCMP and dCTP and the remainder from reduction of UTP.

In host strains carrying $c d d$ and $d d d$ mutations, only deamination of $\mathrm{dCTP}$ and reduction of UTP would contribute to dUTP synthesis. Therefore the fraction of dUTP derived from deamination of dCTP may be estimated by labelling the phage DNA with radioactive dCyd or Cyd in the $c d d-1 d d d-3$ mutant or by labelling with radioactive dCyd in the $c d d-1$ $d d d-3$ crk-3 mutant. The average value for dUMP*/dCMP* in the three cases was again $0 \cdot 5$ (Table 3 ), indicating that the absence of host dCMP deaminase is probably compensated by phage induced dCTP deaminase.

\section{DISCUSSION}

The labelling technique used in the present study to evaluate the contributions of UTP reductase, dCMP deaminase and dCTP deaminase in the synthesis of dUTP may be valid only if the turnover times of the nucleotide pools are short in relation to the labelling times. Neuhard \& Thomassen (1971) have shown that the half-life of nucleotides in Escherichia coli at $37^{\circ} \mathrm{C}$ was much less than $1 \mathrm{~min}$. In $B$. subtilis, radioactive pyrimidine bases and nucleosides are incorporated completely within a few minutes (unpublished data), indicating that the turnover times in B. subtilis may also be very short. Our previous work (Tomita \& Takahashi, 1975) showed that host DNA in PBS1-infected cells is fragmented but is not degraded to acid-soluble nucleotides, and similar results were obtained under the present experimental conditions. Therefore the radioactive precursors used in this study cannot be diluted by the products of host DNA degradation.

The interpretation of the results presented in Table 3 may be facilitated by expressing the specific radioactivity of the dUTP pool $(a)$ as a weighted average of the specific radioactivities of the dCMP pool $(b)$ plus dCTP pool $(c)$ plus UTP pool $(d)$. If the fraction of dUTP derived from UTP reduction is $x$ and the fraction derived from dCTP deamination is $y$, the fraction of dUTP derived from dCMP deamination would be $1-x-y$. Then the specific radioactivity of the dUTP pool $(a)$ can be expressed as:

$$
a=x d+y c+(1-x-y) b
$$

The ratio of the specific radioactivity of the dUTP pool to that of dCTP pool is:

$$
a / c=x d / c+y+(1-x-y) b / c
$$

The value of $a / c$ can be obtained experimentally from the ratio $\mathrm{dUMP}^{*} / \mathrm{dCMP}^{*}$ in the phage DNA.

Equation (2) can be modified according to the mutations borne by host strains. Since 
UTP will not be labelled by radioactive dCyd or Cyd in mutants carrying a $c d d$ mutation, equation (2) becomes:

$$
a / c=y+(1-x-y) b / c
$$

In mutants carrying a $d c k$ mutation, dCMP will be derived only from dCTP and therefore $b=c$. In this case, equation (3) becomes:

$$
a / c=1-x
$$

Experimentally $a / c$ was found to be 0.53 in a $c d d-1 d c k-3$ mutant (Table 3). Therefore the fraction of dUTP derived from UTP reduction and that derived from dCMP and dCTP deamination are 0.47 and 0.53 , respectively.

It was not possible to distinguish unequivocally the contribution of dCMP deaminase and dCTP deaminase in the synthesis of dUTP by the present technique. Nevertheless, the following analysis suggests that deamination of both dCMP and dCTP is important in the formation of dUTP. Equation (3) can be rearranged as:

$$
b / c=\frac{a / c-y}{1-x-y}
$$

The value for $a / c$ was 0.50 with $\left[5-{ }^{3} \mathrm{H}\right] \mathrm{Cyd}$ and 0.97 with $\left[5-{ }^{3} \mathrm{H}\right] \mathrm{dCyd}$ in a $c d d-1$ mutant (Table 3). Therefore:

$$
(b / c)_{\mathrm{cyd}}=\frac{0.50-y}{1-x-y} \quad \text { and } \quad(b / c)_{\mathrm{dCyd}}=\frac{0.97-y}{1-x-y}
$$

Combining these two equations:

$$
\frac{(b / c)_{\mathrm{dCyd}}}{(b / c)_{\mathrm{cyd}}}=\frac{0.97-y}{0 \cdot 50-y}
$$

The ratio $b / c$ is determined by the degree of dilution of specific radioactivities in the dCTP and dCMP pools by non-radioactive compounds derived from the reduction of CTP and phosphorylation of dCyd. Since PBS1 infection did not change the level of these two enzyme activities, $(b / c)_{\mathrm{dcyd}}$ and $(b / c)_{\mathrm{Cyd}}$ may be substituted by the values obtained with uninfected cells. In a separate study, we found that the ratio of the specific radioactivity of dTMP* to that of dCMP* in B. subtilis DNA was 0.62 for $\left[{ }^{14} \mathrm{C}\right] \mathrm{dCyd}$ and 0.19 for $\left[{ }^{14} \mathrm{C}\right] \mathrm{Cyd}$ in a cdd-1 mutant (unpublished data). Since the ratio dTMP*/dCMP* in the DNA is determined by the ratio of the specific radioactivity of the dCMP pool to that of the dCTP pool (see Fig. 1), the values for $(b / c)_{\mathrm{dCyd}}$ and $(b / c)_{\mathrm{cyd}}$ will be 0.62 and 0.19 , respectively. Substituting these values into equation (6) and solving for $y$ gives: $y=0 \cdot 29$. Since in the $c d d-1$ mutant about $50 \%$ of dUTP is derived from UTP reduction, the above result suggests that about $30 \%$ of dUTP is derived from dCTP deamination and about $20 \%$ from dCMP deamination.

Financial support for this work was provided by a grant from the National Research Council of Canada (A-1996). We wish to thank Darryll Bradford for technical assistance. 


\section{REFERENCES}

KAHAN, F. M. (1963). Novel enzymes formed by Bacillus subtilis infected with bacteriophage PBS 2. Federation Proceedings 22, 406.

Neuhard, J. \& Thomassen, E. (1971). Turnover of the deoxyribonucleoside triphosphates in Escherichia coli $15 \mathrm{~T}$ during thymine starvation. European Journal of Biochemistry 20, 36-43.

Rima, B. K. \& TAKAHASHI, I. (1973). The synthesis of nucleic acids in Bacillus subtilis infected with phage PBS1. Canadian Journal of Biochemistry 51, 1219-1224.

Rima, B. K. \& TAKahashi, I. (1977). Metabolism of pyrimidine bases and nucleosides in Bacillus subtilis. Journal of Bacteriology 129, 574-579.

Rima, B. K. \& TAKAHASHI, I. (1978a). Synthesis of thymidine nucleotides in Bacillus subtilis. Canadian Journal of Biochemistry 56, 158-160.

Rima, B. K. \& TAKahashi, I. (1978b). Deoxyribonucleoside-requiring mutants of Bacillus subtilis. Journal of General Microbiology 107, 139-145.

TAKAHASHI, I. (1961). Genetic transduction in Bacillus subtilis. Biochemical and Biophysical Research Communications 5, 171-175.

TAKAHASHI, I. (1963). Transducing phages from Bacillus subtilis. Journal of General Microbiology 31, 211-217.
TAKahashi, I. \& MARMUR, J. (1963). Replacement of thymidylic acid by deoxyuridylic acid in the deoxyribonucleic acid of a transducing phage for Bacillus subtilis. Nature, London 197, 794-795.

Tomita, F. \& TAKAHASHI, I. (1969). A novel enzyme, dCTP deaminase, found in Bacillus subtilis infected with phage PBS1. Biochimica et biophysica acta 179, 18-27.

Tomita, F. \& Takahashi, I. (1975). Changes in DNase activities in Bacillus subtilis infected with bacteriophage PBS1. Journal of Virology 15, 10751080.

Tomita, F. \& Takahashi, I. (1976). Changes in enzyme activities in Bacillus subtilis infected with bacteriophage PBS 1. In Microbiology-1976, pp. 315-318. Edited by D. Schlessinger. Washington, D.C.: American Society for Microbiology.

WU, R. \& KaISER, A. D. (1967). Mapping of the 5 -terminal nucleotides of the DNA of bacteriophage lambda and related phages. Proceedings of the National Academy of Sciences of the United States of America 57, 170-177.

Yamagishi, H. \& TAKAHASHI, I. (1968). Transducing particles of PBS 1. Virology 36, 639-645. 